\title{
Early Childhood Perceptions of Diversity: A Case of Addressing Multicultural Education in the Classroom
}

\author{
Ashley McRae \\ Ashland University \\ Jason Brent Ellis \\ Ashland University
}

\begin{abstract}
This evaluation-based case study research focused on the on how elementary school children perceived diversity in a homogeneous community and analyze how teaching practices can act as an agent to toward and against multicultural pluralism in the classroom. Visualbased methods were used with participants as first grade children were asked to take pictures in the school setting of what they interpreted as diverse. Findings suggested that early childhood students saw the physical manifestation of diversity in many ways and hidden curriculum in the way teachers choose to display diversity in the classroom may hold the key to unlocking a more multicultural curriculum.
\end{abstract}

This study focused on how elementary classroom structures, including curriculum materials and aids, and instructional practices can act as agents for and against diversity and multicultural education in the classroom. This research is presented in the form of a case study on one classroom where children were asked to documents what they perceived as diverse in their school environment. As such, it was hoped that this study would provide insight into the tensions between perceptions and pedagogy regarding diversity and multicultural education with early childhood students.

McCarthy (1998) rationalized that introducing other cultures into the school environment can be as simple as choosing a diverse canon for the classroom. That is, multicultural curriculum can start in the introduction of literature in the classroom with books pulled from varying cultures, languages, and themes that are pertinent to certain societies. Unfortunately, there seems to be an issue with the rather skewed content presented in students' text books, especially in the United States. Student textbooks printed for U.S. classes are concerned with happenings within U.S. borders and sometimes narrowed down even further into specific cultures' views. Other countries' text books introduce new cultures' practices and do not concentrate on their own more than others (Pinar, Reynolds, Slattery, \& Taubman, 1995).

With best intentions, educators have tried various methods to make their classrooms align with multicultural learning environments. Educators have tried 
"changing texts to include the works and experiences of people of color, women, and homosexuals; supporting new pedagogical approaches; and funding inservice seminars to acknowledge learning style differences and multiple intelligences" (Chapman, 2008, p. 44) to make a more multicultural diverse environment for their students. Yosso (2002) argued that multicultural education should not just take an iconic approach in the form of books written by authors of diverse backgrounds or posters in the classroom with various ethnicities represented; rather, it would require a proactive change in "curricular structures, processes, and discourses" (p. 93).

In 1954, Brown vs. Board of Education brought problems of segregation in schools to the forefront. The fact that this was fairly recent in America's history may be the reason that the public schools' policies and regard for multicultural education in the United States are still in disarray. Gay (2004) succinctly translated what the court ruling meant for schools:

\begin{abstract}
Brown sparked a number of legal and social changes that laid the foundation for a broader civil rights consciousness movement in which other ethnic minorities, women, the elderly, the poor, the disabled, and gays demanded that prohibition against discrimination and separation extend to them as well. It also opened up floodgates of opportunities for school practitioners to pursue educational equality on multiple fronts, and in many different ways. One of these was multicultural education. (p. 197-198)
\end{abstract}

Policies regarding equity and equality were made for schools following this hearing, but were either ignored or misunderstood by educators on how to implement them. Chapman (2008) points out that desegregation was goodreverting to segregated schools would be a disgrace to America; but, problems arose when African-American students were placed into schools with all white teachers, who did not adequately represent the minorities' needs in the classroom. There are teachers in America who still live and work in towns of one race and may also feel uncomfortable in their ability to teach a student who may enroll into their class and are of another race. All teachers should be trained to not just survive, manage, or handle multicultural learning environments; they should be trained to thrive in them. Even if a teacher was to only teach one race or ethnicity during his or her entire teaching career, teachers still need to expose their students to new cultures through authentic curriculum, which is why multicultural education should be a higher priority in teacher education. What schools have been trying to do for the betterment of multiculturalism have focused on "remedies-forced busing, magnet schools, race-based staffing ratios, special intervention programs for 'at-risk students" (Fossey, 2003, p. 28). The outcome has been a series of problematic, segregated, and unproductive programs. Thus, administrators and educators have ineffectively tried to create a relevant multicultural learning environment for 56 years.

Some schools still face difficulties with accepting all ethnicities and races in their classrooms. A reason for this reluctance to change in American public schools might be because the United States has been primarily disconnected with racism, slavery, and the use of Jim Crow laws (Callan, 2002). The challenge still exists for curriculum writers and administrators to create something that does 
work, instead of constantly trying methods that might work. The depressing fact is "urban schools 'try' almost everything. While projects are not systematically offered or evaluated, they abound. Inevitably, this plethora of projects...has unforeseen consequences and unforeseen impact" (Haberman \& Post, 1998, p. 100). Chapman (2008) suggests that to move away from merely having theories to having concrete steps of creating a multicultural experience, educators must "document the processes as well as the outcomes" (p. 62). In the meantime, children are not experiencing a multicultural education and growing into globally competent citizens who are aware of, and respectful for, cultures different than their own.

Pinar et al. (1995) also observed that curriculum is not deserving of all the blame from the lack of multiculturalism in the schools; teacher education shares in this blame. Pinar et al. note that the training teachers receive is not conducive to supporting learning about multiculturalism in the classroom. Because of the unprepared nature of teachers to address multiculturalism in their curriculum, teachers "suffer from tendencies to: (a) treat cultures other than the dominant one as both exotic and monolithic, (b) represent these cultures through food-andfestival events, and (c) regard racism as an isolated matter of individual ignorance among certain segments of the population" (Willinsky in Pinar et al., 1995, p. 326).

The preparedness of teachers, however, is not the entire reason for the lack of multicultural curriculum. Since the Brown vs. Board of Education hearing, schools have not automatically reformed to become an appealing place for all learners. It is unlawful for any school in the United States' public education system to discriminate against anyone based on race, gender, or sexuality. Unfortunately and unimaginably though, some schools have found ways around this precedent by showing wilful discrimination. Various ways that schools are still managing, in the twenty-first century, to discriminate against their students include, "student tracking and ability grouping; within school segregation; student assignment; faculty and equipment disparity; employment disparities; staff assignment; transportation; extracurricular activities; bilingual education; special education; and composition of the Board of Education" (Chapman, 2008, p. 48). In fact, one school in the United States, North High in Boulder City, Nevada, was found guilty of all of the aforementioned discriminatory acts from 1993 to 2003 by the U.S. Federal District Court (Chapman).

An important factor to note is that some believe the American spirit and patriotism will be lost if multicultural education is embraced. Callan (2002) believes that multiculturalists need a dose of reality as he states:

[Multiculturalists] prefer...to talk about the need to celebrate diversity, resist ethnic oppression, and abjure coercive assimilation, as if the importance of these things relieved them of responsibility to address the need for continuous and resilient democratic forms that would permit the orderly pursuit of democratic politics. (p. 468)

Multicultural beliefs may be hopeful, but in a country where there is such diversity the need to learn about other cultures is more prevalent than ever. The establishment of public schooling was created in the nineteenth century to 
"ensure the strength of established political (and economic) institutions from one generation to another, and critical to that task was the inculcation of patriotism" (Callan, 2002, p. 469). This is an important point to focus on when discussing multicultural education. While studying so many different cultures, students may find themselves distancing from what it means to be an American.

Callan (2002) points out that patriotism is important to a country's survival: "National myth is so powerful because its widespread acceptance absorbs the loyalties and responsibilities of ordinary citizens within a glorious past of shared achievement, with epic victories and tragic defeats, heroic leaders and despicable enemies" (p. 469-470). History books at times do read like Homer's Iliad, but America's triumphs do provide stories and reasons for unity. Callan just does not believe that a strong sense of unity and patriotism can exist with a public education system based on multiculturalism. The "Utopian" myths of American history no longer exist, which breaks down any patriotic unity-especially among people with ethnicities belonging to suppressed groups of America's past, argues Callan. With the documents discovered in the past hundred years, our history is not just compiled of major events. Now, every person has a story and each one makes up the United States' history. Americans no longer have to look at groups but can instead focus on individual stories of coming to and living in America (Callan). For instance, heroes do not just include the Pilgrims and the Presidents anymore; now, specific Irish immigrants' and Mexican migrant workers' stories are recorded in history books. The variations in instructional delivery then arise when teachers are faced with teaching these stories and how they choose to address them in their own classroom. The other question left unasked from Callan's argument is whether curriculum will begin to celebrate the collective assimilation of cultures into becoming collectively American or celebrate the culturally and historically relevant differences of the peoples who make up American society.

The current study focused on three primary research questions tied to the literature. Much is said in the literature about systemic failings of schools and school districts about not fulfilling the goals of multicultural education, but we sought to get answers on how multicultural education manifests in the classroom as representation of diversity in terms of physical structures and instructional practices through the critical perception of the early childhood student. As such, we looked at: (a) how children perceive diversity in the classroom, as iconic and trivial or as truly representative of a specific culture; (b) whether children perceive cultural diversity in curricular materials; and, finally, (c) whether instructional materials are focused on assimilation into a collective America or whether difference are celebrated.

\section{Methodology}

A case study format was utilized for this study "because of its ability to explain the casual links in real-life interventions that are too complex for surveys of experimental design" (Merriam, 1988, p. 29). As such, one first grade classroom was used with a homogeneous population of Caucasian students. The case study format was also deemed appropriate because this study was also of an evaluative nature in which description, explanation, and judgment (interpretation) were all components (Merriam). 
To properly view children's perspectives of diversity within their school, the children were asked to photograph what they saw as diverse. These photographs would prove to be snapshots into the mind of a child and show pure, rare glimpses of a child's viewpoint. Twenty first grade students in one class at an elementary school in Ohio were given digital cameras with which to take their photographs. Each child received instructions of how to operate the cameras. These children in particular were chosen from a small school in central Ohio which is populated predominantly with local, rural, students who were Caucasian. In choosing this school, clearly the amount of actual contact with cultural diversity was minimal and the children's exposure to any large variance of diversity would have to be found in the cities near them with higher populations. All of the children were given the same description of diversity:

Diversity can be found wherever you look. Diversity shows how people are different. None of us like the exact same things or live in the same house with the same family. We all have different talents and backgrounds - that's what makes us diverse.

This explanation took into account race, culture, ethnic diversity, opinions and original thoughts, and variety without using abstract terms. This definition was tailored to an elementary level understanding, thus filtering out expressions that directly point out skin color, religion, or socioeconomic status. All of the photographs were taken in the children's school. This control on the study helped properly answer the primary research questions and identify their manifestations through structures and practices in the classroom. To protect the children's identities, as well as others' in the school, participants were instructed that no photographs were to be taken of people's faces. Teaching staff were instructed to not engage or guide the students in their selection or focus for the photographs. In this manner, children's views were captured providing insight into their emerging formation of the construction of meaning of diversity and how that meaning manifests in pedagogical practices.

To verify interpretation of the data, field observations took place in the classroom for six weeks during the time the children took photographs. This allowed insight into the instruction and practices going on while the students were capturing the data. These observations also allowed verification that the children were working independently without adult guidance that would have move away from the intention of this project.

\section{Treatment of the Data}

The use of visual research to determine findings is not a new concept. Harper (2005) stated that photographs have been used and compiled into "essays" since the early $20^{\text {th }}$ century to depict emotion and feeling of different events and acute family situations. Harper also showed that by using photographs the reader is more likely to remember the significance of the research rather than by using statistics or quotations. The significance of this research can be retained with the readers' memory connected to photos that are specifically connected to a child's viewpoint which will be more pertinent to a teacher working to create a multicultural, diverse environment for his or her students. 
In this study, a focus group was recruited, made up of three early childhood education college students studying at a private University in Ohio, to categorizing the photographs. The intention of using an independent focus group, familiar with the cognitive and social realities of children of this age bracket, to categorize the data was to discover whether new insight would be provided into classroom and school structures without having been in the classroom to witness the instructional and procedural activities surrounding the study. The directions they received before beginning the categorization were as follows:

\begin{abstract}
On this flash drive, there are hundreds of photographs that were taken by elementary students. I need you to put them into categories for a study I am performing. I cannot tell you why the photographs were taken or what the research is about, but I do need you to label the categories in which you place the photographs. If you find that any photographs are too blurry to comprehend or contain people's faces, then I need for you to place those photographs into an 'inconclusive' category.
\end{abstract}

\title{
Findings
}

After the students used the digital cameras for a period of eight days, their cameras were collected and the photographs given to the focus group. After one hour and fifteen minutes, the focus group had categorized the photographs into the following categories: Animals; Art; Books and Literacy; Clothing and Accessories; Color; Food; Furniture and other classroom items; Math, Numbers, and Patterns; People; Safety; Technology; Words; and the last category of Inconclusive. One note concerning the "People" category-although the students were not supposed to take photographs of anyone's face, the children did take photographs of characters in their storybooks and magazines that they found in the classroom. After the categorical construction was created by the independent focus group the researchers analyzed these categories for the presence of diversity that promoted possible barriers to multicultural education; in essence, tensions were sought out from the visuals.

\section{Discussion}

Children's abilities to look at things that were diverse covered a wide range of diverse items present within their school. What is evident in the visuals presented here is that children do see diversity in many different ways. Tensions come from the way that these differences are addressed or left unchecked in the classroom. The tensions are discussed on the following broader themes: (a) Difference from Self as Diversity, (b) Representations of Iconic Diversity, and (c) Symbolism of Embracing or Shunning the Other.

\section{Difference from Self as Diversity}

The students in this study identified many differences. It was an original belief of the researchers in this study that rudimentary elements such as colors, shapes, and other concrete visual difference would be present amongst the core representation of which students would focus their photography. While many representations of colors and shapes where present in the data, other elements presented themselves that told a story of diversity in abstract form that hold 
profound social and instructional repercussions. For instance, besides recognizing the differences in types of animals, Taz (Figure 1) is a testament to the fact that children notice difference in speech and mobility-even in more abstract renderings like cartoons. Taz is different from other Looney Toons characters by the way that he moves from place to place and by the fact his speech is incoherent to others around him. By human standards, societal norms would label him with a disability because of his functional limitations in mobility and articulation. As well, his character is also one of the only ones featured in the Looney Toons franchise that is somewhat stocky or overweight. This could also attest to the students' recognition that body shape is a representation of diversity.

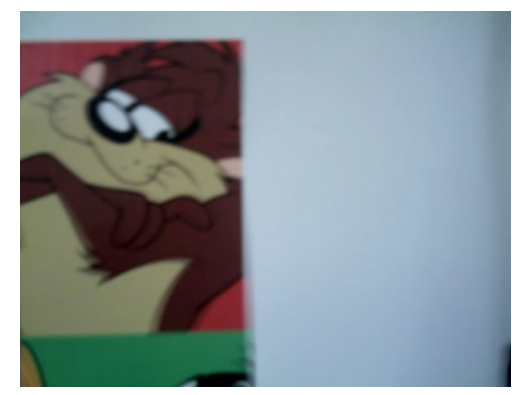

Figure 1: Diversity as ability and body image.

In the books and literacy category, the identification of whether or not students recognize a difference in ability among peers manifests itself. The book boxes (Figure 2) with labels indicating levels of reading ability are marked as a difference in the students' perceptions. In early childhood classrooms teachers traditionally have used a strategy of labeling their reading groups with different letters, team names, numbers, or colors to disguise the fact that their students may be reading at varying levels. But no matter what labels are attached, students easily become aware that ability or deficit to ability are present.
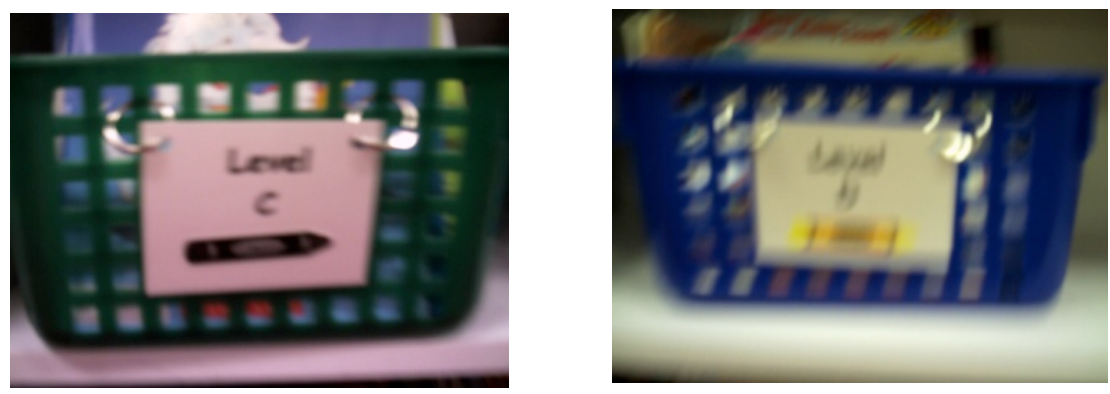

Figure 2: Diversity as ability in reading.

Figure 2 presents the perspective that students know there is a difference among each group and are making comparisons from their own position to where others may be in reading ability. While such practices of grouping children by reading level are common and superficially attempt to reduce stigma by utilizing generic labels for levels of achievement, stigma associated with grouping is 
actually exacerbated because "ability grouping provides fewer opportunities for learning than whole class instruction but with greater utilization of those opportunities" (Sørensen \& Hallinan, 1987, p. 539) or rather that high ability groups are afforded more opportunities for learning than lower ability groups in the classroom and that this deferential treatment of students is easily identified. It is not just the boxes of books by level that add to the difference; it is the different learning opportunities associated with those boxes that perpetuates and accentuates the difference.

Students also identified diversity as difference in gender through their photographs. In the clothing and accessories category, the children photographed shoes, coats, and backpacks to show gender differences in attire. With the line of coats and backpacks (Figure 3), the students captured a clear spectrum of gender differences existing in their own classroom with the pink backpacks and flowered coats for girls and the black, blue, and red displayed for the boys. This difference may be a reflection of what society and media has encouraged the children to purchase or what is entrenched in the current school's curriculum regarding the expectations of gender roles. Kedar-Voivodas (1987) observed teachers' attitudes toward sex roles and learner roles in the classroom. Three classes of learner roles were utilized: (a) the Pupil role depicted as a patient, docile, passive, orderly, and conforming individual; (b) the Receptive role depicted as the student who consistently performs in "established curriculum areas, on prescribed measures, at set times, and by set criteria" (p. 417) and can work without detracting or being distracted by others; and (c) the Active learner role depicted by "curiosity, active probing and exploring, challenging authority, an independent and questioning mind, an insistence on explanations" (p. 418). Kedar-Voivodas concluded that "teachers are biased in favor of pupil and receptive learner role attributes rather than those associated with the active learner ... [and] also suggests that whereas pupil and receptive learner roles are compatible with the conventional female sex role, they are in conflict with the male role (predominantly the active learner role).

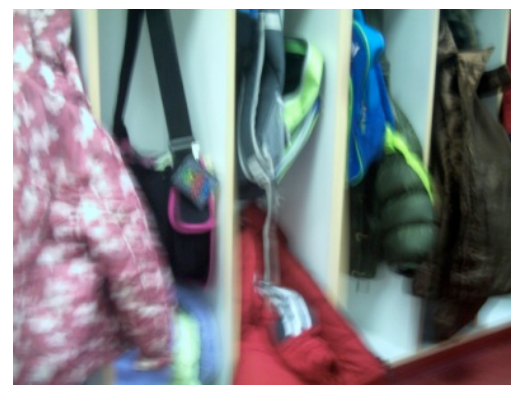

Figure 3: Diversity as gender difference through attire.

Attire in non-uniformed classrooms often personifies itself. For example, a typical girls' outfit may entail pink and flowers, personifying an expectation that females are accepted and encouraged to identify in the pupil and receptive learner roles. In fact, according to Kedar-Voivodas's (1987) findings, this role identification is encouraged because teacher attitudes toward students go hand in hand with achievement. Girls are prompted to play the passive or receptive role 
as their achievement is dependent on this. Males, being more perceptually congruent with the active role, suffer from negative teacher attitudes because of the active learner role, but also have negative attitudes associated with embracing the more passive pupil and receptive roles.

Emotion as diversity was also represented in the photographs of students in this study. Two photographs of the faces (Figure 4) show a polar contrast of emotions. This identification as diversity is important in education in addressing the fact that there are many different emotions that children experience in school. The danger lies in the non-acceptance of the sullen child or the withdrawn, isolated peer, perceiving them as an outsider because of their emotional stance. The issue then becomes addressing this acceptance within curriculum and instruction.
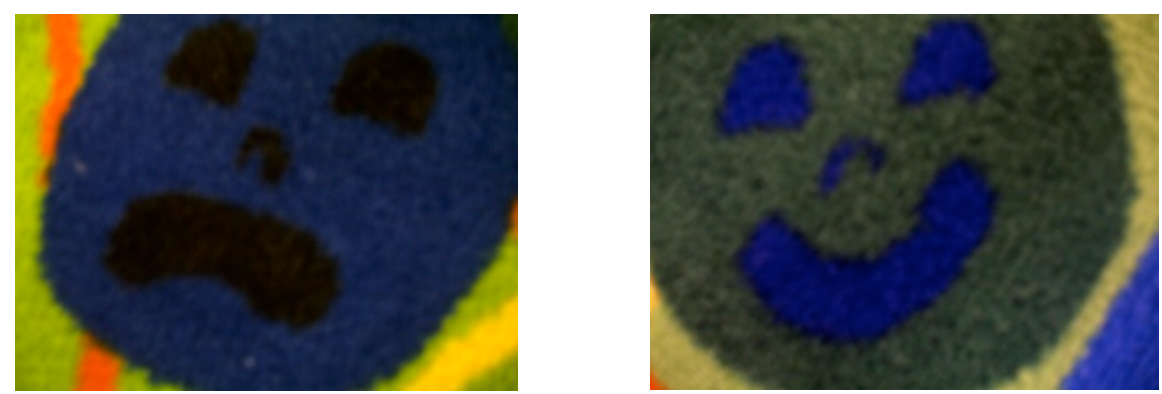

Figure 4: Diversity as difference in emotion.

Students' photographs also observed difference in behavior between peers. In the classroom in which this study took place, the levels that children achieved in inappropriate behavior were depicted in individually named clothes pins on a color wheel (Figure 5) in the classroom. Each color on this wheel indicated a different level of discipline that the child would receive for any particular day, in accordance with their behaviors in and out of the classroom. Green indicated no discipline and all; children start their pin on this color. Child must move their pins to yellow if they break one school rule and then in succession to red, where a meeting with the principal and a call home are the consequences. The photographer noticed that the pins were on different colors, but also that one child had managed to move to blue and his pin was all alone, or different. By displaying the behaviors publically on this chart, the students can make quick comparisons between their behavior and others in the classroom and can label themselves and their peers as "good" or "bad" depending on their position on the wheel. This identified difference could lead to stigma and estrangement from the community and provide a label that persists throughout the schooling years. 


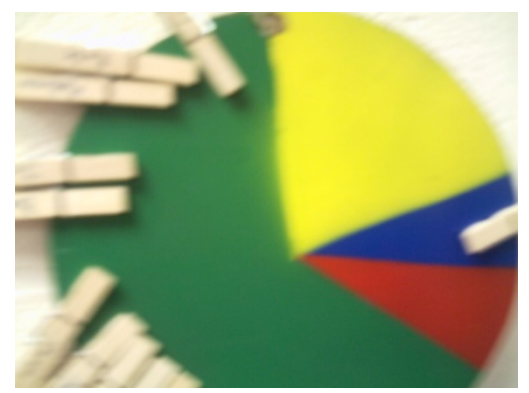

Figure 5: Diversity as difference in behavior.

Although the children were instructed to avoid taking photographs of people, they managed to do so in their own way. The visitor badge (Figure 6) represents the other; someone who is not a student or teacher and is different to their environment and does not belong. This could show that the students are not accustomed to welcoming new guests; or, if visitors are indeed common, then their presence is not incorporated into everyday learning, but rather a background helper. Noddings (2007) has suggested that the outsider or other within or between societies is judged by their difference or solely in the fact that they are not of the group. Noddings writes "when we see evil in the other, we withhold judgment long enough to be sure that the evil is in the other and not a projection of evil in ourselves" (p. 232). In curriculum and instruction the other needs to be studied, embraced, and thoroughly welcomed into the classroom. The other "demands of us an ethical response-unalienable right to be engaged as human beings" (Borg et al., 1998, p. 355). As such, the label of "visitor" itself has the connotation of someone who is unexpected and not necessarily welcomed. If the badge read "guest" instead of "visitor," then the students' concept of the person wearing the badge may not be one of difference, but rather of membership or belonging.

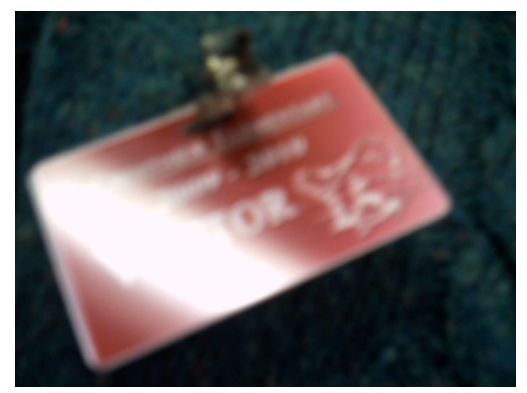

Figure 6: Diversity as the presence of the Other.

\section{Representation of Iconic Diversity}

Iconic diversity we coin as the act of displaying images of diversity without context or addressing its place within the space it is displayed. It represents not necessarily intentionality in its display but can be closely associated with such behaviors as tokenism (displaying diversity to create a false appearance of its presence) and mascotism (displaying diversity as a symbol for a group when it 
has nothing with that particular culture). One student photographer deliberately took a close up picture of the image of what seems to be a woman of color (see Figure 7).

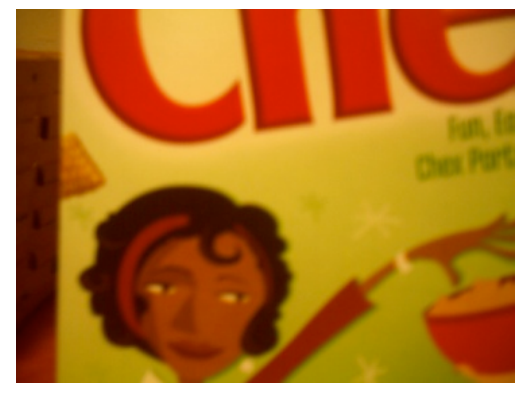

Figure 7: Diversity as race, sample 1.

The intention is clear that the muse of diversity here is not the entire box, but instead a narrowed focus of the woman's face. Likewise, other iconic images appear in the classroom in books and banners like that depicted in Figure 8. Although the books (and cereal boxes) in the classroom represented different races, the lack of a multicultural curriculum addressing cultural differences may make the connotation of these materials depicting different cultures and races as iconic to a group composed of children who are of the same race.

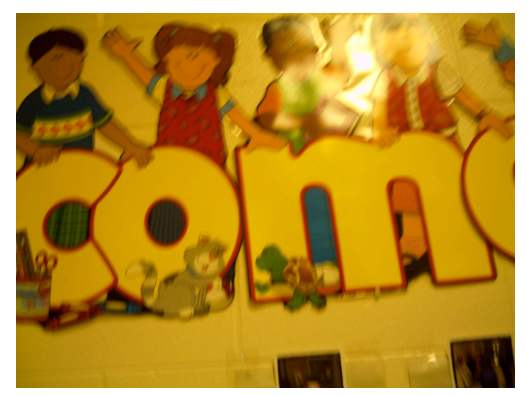

Figure 8: Diversity as race, sample 2.

\section{Symbolism of Embracing or Shunning the Other}

The cutout collage of figures (Figure 9) with differing colored faces and hands is a demonstration of the identification, if not the personification, of difference coming out through curriculum. The collage shows that although students are encouraged to be unique in their artwork, the differences are noticed and compared of physical features and personal expression, such as hair, clothing, facial attributes, and accessories. 


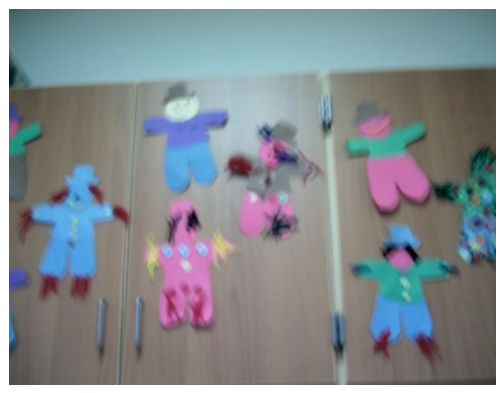

Figure 9: Celebration or assimilation of cultures.

What is of interest, though, is not the figures themselves, but the teacher's choice of arrangement - the physical manifestation as an outcome. Rather than segregating figures by color, the teacher has chosen to mix all different colored figures together. Zou and Trueba (1998) discuss diversity as such a manifestation of cultural blending leading to shared culture, language, and civic responsibility toward the commonality. Obviously, here, it is hard to flesh out whether there is intention of assimilation in this display or a celebration of diversity. Is it the proverbial melting pot of American cultures or one celebrating differences, the fruit salad approach, where there is distinction of cultural richness and difference? From the field observations, we believe that there was not intentionality in arranging the display-diversity was not address - so this becomes another symbolic display left to interpretation of the children in this class.

A similar symbol representative of the classrooms approach to multiculturalism was photographed by one of the young photographer participants. The globe (Figure 10), a wonderful symbol of the holistic diversity present in the world, is seen as out of reach. It is depicted as different or untouchable. Its positioning in the classroom is high above the student's reachalmost touching the ceiling. It is also in the corner of the room where the teacher often has other classroom items placed, thus hindering the accessibility to items in that area. It could simply be that the teacher is concerned that the globe will be damaged by inappropriate use, but, nonetheless, it may serve as a message to the young forming mind that this globe (and perhaps diversity) represents something that is best left at a distance or is trivial and unimportant to learning.

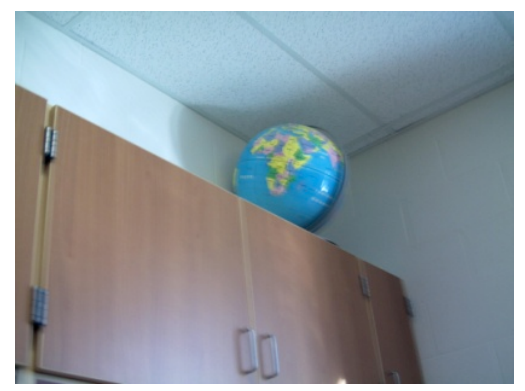

Figure 10: The symbol of diversity at a distance. 


\section{Conclusion}

An important observation from this research is that the students noticed differences in many forms relevant to how adults construct diversity their learning environment. Children in this study observed diversity as manifestations of behavior, ability, race, body type, emotion, and gender as a physical presence in their school environment. This is important to note because the children do see differences, which, these perceptions left unchecked without guidance, may foster into biases and preconceptions. Because children identify these differences, it is imperative that teachers make the effort to address wider constructs of diversity beyond cultural differences that include gender, sexuality, ability, body shape, and a plethora of others, and guide children toward appreciating these differences. For teachers to educate their students about other cultures, they will need literature and proper training for conducting classroom discussions and changing their curriculum to be conducive to multicultural learning.

Visual representations were presented by the students who participated on this study that speak directly to the research questions. Children perceive diversity in the classroom much like adults do in terms of gender, race, and ability. They also identified iconic representations of race from classroom materials. It is left to the interpretation of the reader whether the described instructional materials in this classroom, such as, the collage and globe, were focused on cultural assimilation strategies. What is important, though, is that visual data coupled with observational data from this study illustrates that there is space within instruction to address diversity and multiculturalism to work toward inclusion.

\section{References}

Borg, C., Mayo, P., \& Sultana, R. (1998). Revolution and reality: An interview with Peter McLaren. In W. F. Pinar (Ed.), Curriculum Toward New Identities (pp. 355-376). London, England: Garland.

Callan, E. (2002). Democratic patriotism and multicultural education. Studies in Philosophy and Education, 21, 465-477.

Chapman, T. K. (2008). Desegregation and multicultural education: Teachers embracing and manipulating reforms. Urban Review, 40, 42-63.

Fossey, R. (2003). School desegregation is over in the inner cities: What do we do now? In E.P. St. John (Ed.), Reinterpreting urban school reform: Have urban schools failed, or has the reform movement failed urban schools? (pp. 15-32). New York,NY: New York University.

Gay, G. (2004). Beyond Brown: Promoting equality through multicultural education. Journal of Curriculum and Supervision, 19(3), 193-216.

Haberman, M., \& Post, L. (1998). Teachers for multicultural schools: The power of selection. Theory into Practice, 37(2), 96-104.

Harper, D. (2005). What's new visually? In N. K. Denzin, \& Y. S. Lincoln, (Eds.), The Sage Handbook of Qualitative Research (pp. 747-762). London, England: Sage.

Kedar-Voivodas, G. (1983). The impact of elementary children's school roles and sex roles on teacher attitudes: An interactional analysis. Review of Educational Research, 53(3), 415-437.

McCarthy, C. (1998). The uses of culture: Education and the limits of ethnic affiliation. New York, NY: Routledge.

Merriam, S. B. (1988). Case study research in education. A qualitative approach. San Francisco, CA: Jossey-Bass. 
Noddings, N. (2007). Philosophy of education. Cambridge, MA: Westview.

Pinar, W. F., Reynolds, W. M., Slattery, P., \& Taubman, P. M. (1995). Understanding curriculum: An introduction to the study of historical and contemporary curriculum discourses. New York, NY: Lang.

Sørensen, A. B., \& Hallinan, M. T. (1986). Effects of ability grouping on growth in academic achievement. American Educational Research Journal, 23(4), 519-542.

Yosso, T. J. (2002). Toward a critical race curriculum. Equity \& Excellence in Education, 35(2), 93-107.

Zou Y., \& Trueba, H. T. (1998). Ethnic identity and power: Cultural contexts of political action in school and society. New York, NY: State University of New York Press.

Ashley McRae is a recent graduate from Ashland University's Early Childhood Education program. The idea for this project evolved having studied and student-taught abroad in urban Britain and rural Ireland. This research served as the capstone project for her participation in Ashland University's undergraduate honors program.

A native of Canada, Dr. Jason Brent Ellis has been an assistant professor of instructional and assistive technologies in Ashland University's College of Education since 2007. His research focuses on technology use by students with disabilities in K-16 education, ways of leveling the digital divide through policy and pedagogical interventions, ways of providing access to under-represented and non-traditional students, the creation of sustainable models of education in emerging global economies, and scaffolding in distance education. 